\title{
Influence of Sociocultural Differences in Translating Euphemistic Expressions from English into Arabic in "A Grain of Wheat"
}

\author{
Sameerah Jabbar Anber (Corresponding author) \\ General Inspection Office, Ministry of Culture of Iraq \\ E-mail: Sameera_jabbar@yahoo.com
}

Muna Abdual Hussein Swear

University of Technology, Ministry of Higher Education and Scientific Research, Iraq

E-mail: mona_ode@yahoo.com

\author{
Doi:10.7575/aiac.alls.v.7n.6p.123 \\ URL: http://dx.doi.org/10.7575/aiac.alls.v.7n.6p.123
}

Received: 03/08/2016

Accepted: 18/10/2016

\begin{abstract}
The study investigated the sociocultural differences in translating Euphemistic expressions from English into Arabic. Particularly, the study took the novel "A Grain of Wheat" to show the differences of these expressions usage by two translators from different cultures. The study adapts a qualitative approach applied in Leppihalme's (1997) and Unseth's (2006) translation strategies to focus on the sociocultural differences in translating expressions as; Death, Sex, Human body, Bodily function, since they are the most popular Euphemistic expressions in each culture. The results show that both translators employed omission and literal strategy frequently which may not express euphemistic words functionally. Additionally, both translators attempted to translate the euphemistic expressions semantically at the expense of rendering them adequately into the target culture. However, inspite of the similarities and differences in the employment of translation strategies in translating the euphemistic expressions by both translators, Syrian translation is apparently better delivered than the Iraqi translation. Hence, the findings suggested that knowledge and competence of the translators in handling sociocultural differences as well as the employment of effective strategies such as those proposed by Leppihalme and Unseth are indispensable tools for solving the problems of translating euphemistic expressions.
\end{abstract}

Keywords: Sociocultural differences, translation studies, euphemistic expressions

\section{Introduction}

Euphemism is a linguistic device came from the Greek euphemisms, which means "speaking well". It is used now days in the daily social interactions around the world. Euphemistic expressions indeed used by communicators to let them avoid embarrassment in specific events as in referring to names or words directly (Allan \& Burridge, 2006). Euphemisms are long standing cultural phenomenon in most languages. As social tools, euphemistic expressions are widely used in every level of society to meet certain communicative needs, show respect, humility, and politeness. These tools could make our speech more expressive and colorful since they adapt speech to different situations (Alkire, 2002). Accordingly, Huang (2005) pointed out the individuals often avoid taboos, odious ideas, and what are socially complicated by substituting them with polite phrases and accurate words (2005, pp.46-47).

It is well-known that people in their daily life normally used language to simplify and promote their ideas and viewpoints while communicating. However, due to the unacceptable impact of some expressions in direct communication, sometimes language can be complicated in terms of the meaning of some expressions which might be sound unpleasant in the target society (Cho, 2014). Hence, users of language in every society normally adopt euphemistic expressions in their communication to soften the dislikeable meanings of these expressions since they are often disagreeable in their societies. Euphemistic expressions are used typically as alleviative strategies to soften the unpleasant expressions, replacing them with acceptable alternatives to reserve politeness.

In this vein, Burchfield (1985) the editor of The Oxford English Dictionary pointed out that people often used euphemism to avoid making language as defective tool in their communication (Alkire, 2002). Accordingly, it can be understood that the interpretation of indirect expressions is socioculture specific. In other words, translators are influenced by the specifications of their societies through the process of translating euphemisms. For example, sometimes the usage of euphemistic expressions is related to the social class, hence some are more sensitive towards class division. This is can be noticed obviously in the usage the euphemistic expressions like "economy class" by some societies instead of "second class" in order to avoid appearing apparently inferior. Or, in referring to death which enduring ideas that are euphemised in many cultures, hence societies express and refer to it differently. People have different insights to refer to death, and then, the expressions they practice to talk about. Many phrases such as "passing away" and "putting to sleep" are death-related euphemisms for dying and euthanasia correspondingly.

Unpleasant expressions are in general acknowledged to be socialcultural phenomena associated with illogical beliefs, customs and norms. The employment of euphemistic expressions in social contexts may differ in most of them due to 
cultural backgrounds associated with languages' differences. While some situations require the use of euphemistic expressions in some cultures, the others find using of them for such situations unnecessary. Thus, such case may lead to misunderstanding and could deprive the source languages from their cultural traits. Regarding little knowledge of euphemisms creating misunderstandings in communication, people maintain confirmatory attitudes. It was claimed that lack of knowledge about euphemistic expressions may cause problems to perceive and convey some messages correctly.

Translating from one language into other abounds with various problems. Casagrande (1954, p.335) calls for the treatment of translation as a primarily cultural act. This call highlights basic relationship between culture and translation. Culture poses problems to the translations due to the existence of cultural gaps between the occident and the orient languages, a gap to which some scholars attribute the process of employment the Arabic texts undergo. Venuti (1996, p.196) argues the reconstruction of the foreign text in accordance with values, beliefs, and representations that pre-exist in the target language. Although we can show politeness without using euphemism (by choosing more formal vocabularies), euphemism helps to be polite in speech and behavior because some expressions have negative meanings and may show impoliteness. Euphemistic expressions inspire from cultures, religions, taboos, and aesthetic features of societies, people can become aware of similarities feel writer's aims more tangible by extending their knowledge about source and target cultures because most cultures have something in common.

\section{Cultural Differences between the Source Language and the Target Language}

The process of communicating Euphemisms meanings from the source culture into the target culture has proved to be challenge issue. Such challenging lies in the fact that what is considered culturally suitable in the source language might be considered as unacceptable in the target language culture. For example in translating the English phrase "blood of ram" an Iraqi translator rendered the phrase into "blood of sheep", which is unrelated alteration to the source language, therefore, it sounds meaningless. Accordingly, Culture-bound expression that is deeply rooted in the structure of the language cannot be effortlessly reproduced in a corresponding method (Abdul-Raof, 2013). Hence, translating the cultural expressions can be a problematic task. Nida (1964, p. 130) believes in equal significance to linguistic and cultural differences in translation between the SL and the TL. Nida noted that for translators cultural differences are more complicated than differences in languages structures. Euphemisms are the cultural expressions; their renditions are unquestionably difficult to some translators.

Moreover, each country has its geographical conditions, people's habits, religious beliefs and ideas that form its people's unique culture. The differences between two or more cultures may cause one nation believes in some events and habits which are strongly odd or forbidden to another. The cultural obstacles lie in conveying the flavors of euphemistic meanings in the SL which cannot be achieved unless the translators discover appropriate equivalents in the TL (Borini, 1994).

Facing euphemistic expressions in SL, the translators may have sense of inability to convey the specific meanings to the TL. Sometimes translators will get confused in this way. To convert texts from SL into TL, a good understanding of the culture is required, especially the target cultures. This process requires several studies and investigations on the SL and TL cultures. Thus, translators must be familiar with these cultures to distinguish the kind of the expression. Accordingly, there are two possibilities:

1- The euphemistic terms in the source language are not euphemistic terms in the target, so the translators have no problems and will render these expressions directly.

2- The euphemistic terms which are not euphemisms in the source language are euphemistic terms in the target and in this case there are some choices to convey.

In a nutshell, translating euphemisms culturally is not an easy task (Mohammad, Mohammed \& Ali, 2007). It requires overwhelming knowledge, cultural influence and accuracy on the culture of the SL and TL languages (Holden \& Von Kortzfleisch, 2004). The influence of cultural difference between the two languages is a great obstacle in interpretation. Thus, translators would be in despair to detect the accurate correspondent of euphemism that is restricted in its selection to definite collocation. Such choice is based on the semantic connection relating to the two collocations.

\section{Problem Statement}

Euphemisms by definition are figures of speech that covered ideas meaning that are not typically express precisely the meaning of the individual expressions. Euphemisms are substitutions of indirect, mild, or vague expressions used to mask and apparently indicate expressions that are thought to be harsh, offensive, or dishonest (Dumarsais as cited in Charaudeau et al, 1998, pp.241-242). Euphemisms in translation pose major problem specifically in translating texts that related to religions and cultures which might be have different insights among societies (Shehab, E., Qadan, A., \& Hussein, M., 2014).

Research related to euphemism has its long interest to languages, aspects, forms, and functions. Scholars collected data from movies, presidential inaugural address, political debates and speeches in newspapers, comedies and novels. For example, in policy Prasetyo (2015) focused on euphemism usage in Obama's Presidential Debate of the United States (2012). In movie, Dhika and Gede (2014) classified types of euphemistic and dysphemistic expressions in "Remember Me" movie. In media, Cardova Efendi, Rusdi Noor Rosa, Delvi Wahyuni (2013) analysed the types and forms of euphemism used in online mass media. On the other hand, Laura Samoškaite (2011) examined theoretical approaches and studied the concepts and features of euphemisms in today's English Newspapers (county) while Musfiroh (2014) studied euphemistic terms used by Barak Obama in his inaugural address.

It can be noticed from above that to date, the strategies for translating euphemisms proposed by two scholars Leppihalme (1997) and Unseth (2006) focusing on euphemism translation strategies have not been deserved its proportion of research yet. Additionally, in Arab literature it has been noticed that the number of studies on euphemism, studies on euphemistic expressions related to strategies applied to the translation of literary works from English to Arabic are insufficient. As a case of study, using these strategies in translating texts from English to Iraqi and Syrian are ultimately very rare. Euphemisms used in the source text are related to elements of translation which include culture, 
society, and religion. Hence, there is a significant problem in interpreting the source of euphemism that requires choosing appropriate alternatives to express the hidden meanings found in the original text. In fact, this study touches upon euphemistic expressions as a cultural gap and as one of the most problematic area.

Translating to Arabic sometimes imposed certain necessities on Arabic translators. That is why some Arabic translators in our case of Iraq and Syria, employed methods that occasionally alter the original meanings and ruined the beauty of the expressions being translated. In this vein, some authors in Iraq and Syria, as Basim Mohammed (2015) Abdul Jabbar Mohsen Al-Rubaiy (2014), Omar Talib (2014), and Mourice Abu Nazer (2014) pointed out that literary translation in Iraq often full of uncertainties and consequently not encouraging. The majority of contemporary Iraqi translators are not competent enough to convey the actual meaning of the texts may be because they are necessarily untrained. Accordingly, translation has been faced with countless obstacles and suffering negative impacts, therefore readers often try to read the original text rather its translation.

The issue of using effective strategies as that proposed by Ritva Leppihalme and Peter Unseth to analyse euphemisms expressions as a challenging phenomenon in Arabic translation where there are a lot of the employment of inadequate translation strategy of euphemisms is significant in order to gain understanding and insights about how to cover this problem amongst English-Arabic translators.

\section{Research Questions}

In tandem with the objective, this study suggests the next research question:

How the sociocultural differences affect the translation of the euphemistic meanings in "A Grain of Wheat" from English into Arabic?

\section{Methodology}

To bring the problem under discussion into concentration, the current study adapts a qualitative approach applied in Leppihalme's (1997) and Unseth's (2006) translation strategies. Leppihalme's strategies are: (1) standard translation usage, (2) minimum change that means literal translation, (3) additional euphemistic expression, (4) Footnotes or endnotes employed, (5) replacement using a target language term, (6) reduction of euphemisms, (7) adaptation, 8) retention and (9) omission. Unseth's strategies are four strategies: plain language usage, literal Translation, render the source using different one, and practice a mixture of two tactics of the aforementioned. On its the practical side, it is employed a textual analysis method.

This study involves 24 English euphemisms in the "A Grain of Wheat" novel "Habaa Al-Qamh" by the Kenyan author Ngugi's Wa Thing'o (1967). Euphemismtic expressions are categorized into death, sex, body parts, and bodily function based on the catergorization of Allan and Burridge (2006). Figure (3.4) below shows methodology.

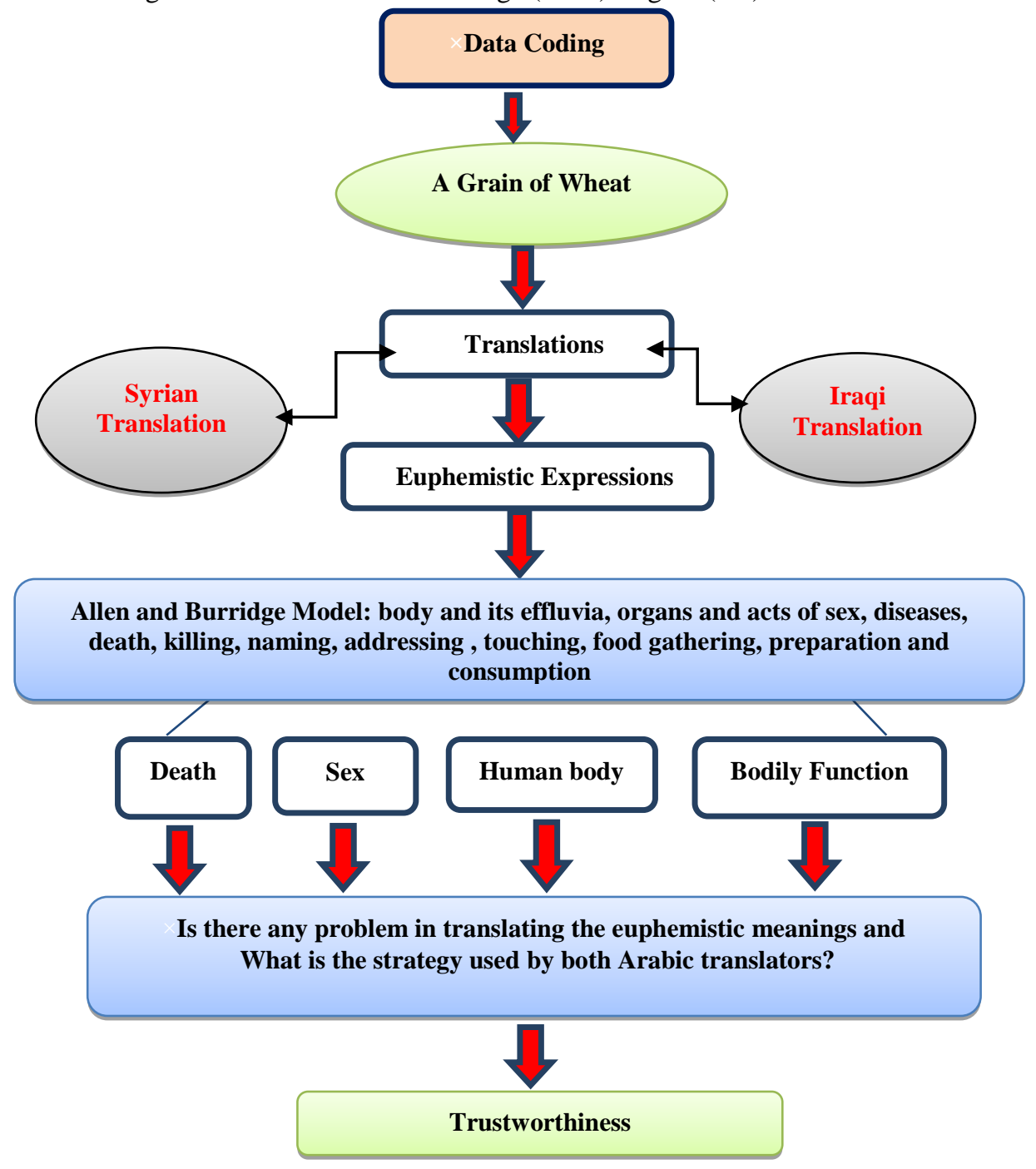

Figure 1. Methodology 
Four significant reasons underline the choice of Ngugi’s novel "A Grain of Wheat". Ngūgî’s famous 1967 novel "A Grain of Wheat" is a complex one with multiple narrations spanning a significant period in the history of Kenya dealing with colonial encounter and decolonisation. It signifies his latest work published in English language due to the negative attitude that was taken by him against this language. One of the most striking aspects of the novel is the method of its narration. This work proved its thrust in realising how writing could be instrumental to progress.

\section{Analysis and Discussion}

\subsection{Death Euphemistic Expressions}

Each culture has always explored various techniques to mask the death event because people have always found it difficult to express it directly. Euphemistic expression was the preferred approach used in such events. Free-based offensive word in which varied fears arise, such as fear of the loss of loved people, fear of body's corruption and several fears that exist after death (Allan \& Burridge, 1991, p.30). Let us consider the next example in (p.22):

\section{Text 1}

\begin{tabular}{|c|c|c|}
\hline$\overline{\text { ST }}$ & TT Syrian & TT Iraqi \\
\hline \multirow{2}{*}{$\begin{array}{l}\text { "He always went out alone to } \\
\text { finish off a dangerous } \\
\text { character" (p.22) }\end{array}$} & شخصية خطرة. يخرج غالباً وحياً للإجهاز على & غالباً ما كان يذهب ليصفي شخصية \\
\hline & $\begin{array}{l}\text { "He often goes out alone to finish } \\
\text { off a dangerous character" }\end{array}$ & $\begin{array}{l}\text { "He often goes out to } \\
\text { murder } \\
\text { character" }\end{array}$ \\
\hline
\end{tabular}

In the story, the author frequently uses the expression "Finish off" as a euphemism of kill. This verb is used on humans or animals. If they have been previously wounded or are sick, you finish them off (Holder, 2008). The author is deliberately using euphemistic expressions, indeed exaggerating their employment, to show and understand how the vocabulary and syntax of a language may be used to shape reality. The source death text of the author was rendered by both translators of Arabic versions differently. Mahfouz retains the euphemism “finish off” (إجهاز) which means speed up to kill the intended person until death.

Mahfouz's optimal choice does euphemistically and communicatively convey the intended connotation. He is aware of the importance of context in keeping the spirit of the original text and able to comply with the intentional connotation in the source text that would make it sound accepted in the target text.

The strategy employed by Mahfouz in translating this expression was Unseth's strategy of minimum change, that is, literal translation. Unseth (2006) says that literal translation may be applied if both the original and the target texts share similar euphemistic expression. Accordingly, such translation is conventional since it will intend the implicit meaning. In this example, we can see that in contrast with Mahfouz's translation, Hassen uses the Arabic verb "Yusafi" "fint which indicates deliberately premeditated murder (Al-Waseet Dictionary, 2004). Hassen renders "finish off" into dysphemistic word "Yusafi" and "murder" is used instead. Murder is a legal term for an "unlawful, malicious, and intentional killing" (Rawson, 1981, p.158).

The two translators have translated the euphemism in different ways. Mahfouz translates it literally and is concerned with the correspondences. Nida and Taber (1969) say: when translator focuses his attention on the messages, these messages will emanate from forms and contents. It is obvious that in most of his rendition, Mahfouz has frequently employed word for word translation by choosing very common denotative connotations of the STs. In other words, his translation imitated the forms of the source messages which are lexical contents. Nevertheless, the targeted readers will not find such translation blunt to read. However, Hassen has altered the source expression by using different translation strategy.

Accordingly, the euphemistic expression in the source text and its two translations into the TSs are unrelated. This proposes that, different cultures employ varied inoffensive expressions.

The source term "finish off" would have been better if the two translators of the target language used the minimum change strategy of Leppihalme, that is, a literal translation. Thus, Leppihalme's strategy will consider the base for the suggested translation of the original expression "غالباً ما كان يخرج للقضاع على شخصية خطيرة","He always went out alone to terminate a dangerous character". “للقضاء” means death (Lissan Al-A'arab Dictionary, 1968). Rawson (1981, p.279) identifies terminate as a word for murder; means end a life of something or somebody. Holder (2008) defines terminate as to kill, and literally, to end. 
The next example on (p.7) illustrates more:

Text 2

\begin{tabular}{|c|c|c|}
\hline ST & TT Syrian & TT Iraqi \\
\hline \multirow{4}{*}{$\begin{array}{l}\text { "You would have } \\
\text { followed your father } \\
\text { to the grave" (p.7) }\end{array}$} & لكنت لحقت بأبيك الى القبر & كنت ستلحق أبيك الي القبر \\
\hline & (p.19) & (p.25) \\
\hline & "You would follow & "You would follow \\
\hline & your father to the grave" & your father to grave" \\
\hline
\end{tabular}

Here, as well, the verb "follow" denotes the intended person in the novel who went to meet his father with Allah (God). The expression in the source text is inoffensively employed to express the world after death and make individuals have a spiritual dependence, living quietly, and leaving with a smile in the end. In the source text, the above euphemistic expression for death is described as a movement to a definite destination. Moreover, grave means the death; it is a Standard English figurative use (Holder, 2008, p.203).

Farghal and Shunnaq (1999, p.107) state that lexical items could be pleasant to certain receivers but offensive to others. For instance, the Arabic word "قبر" (grave) will commonly have a "negative" implications for those who have lost their beloved persons, while it may possibly have a "positive" connotation for "حفار القبور" (grave digger), who makes a living from grave digging. Both Arabic translators Mahfouz and Hassan employed successful translation in rendering the same verb (التحق)), "follow", that is, the two persons in the novel went with their God. "Follow" in according to Holder (2008, p.184) is to die after another named person to be reunited elsewhere.

The two translators have translated the euphemism literally and followed the same method used in the ST. The source and target items are close enough in their meaning that allowed for literal choice to be made between them in their contexts. The above translations have employed a literal translation which imitates the structure of the source by choosing a very common denotative meaning.

Hence, the two Arab translators applied the strategy of Unseth's strategy of a minimum change, that is, a literal translation. The verb "يلتحق" which means die in the Arabic language could be used as a synonym for the verb "follow" (Dictionary of the Contemporary Arabic Language, 2011). The verb" "يلتحق" refers to the phrase "depart the life", that is, pass away (Holder, 2008, p37). Subsequently, the suggested translation is in accordance with the strategy proposed by Unseth which focuses on translating the original term by using different one of similar meaning in the TL (لألتحقت بالباري كابيك), "To depart to Allah as your father did".

In another example on (p.143) shows the author usage of euphemism:

\section{Text 3}

ST TT Syrian $\quad$ TT Iraqi

\begin{tabular}{|c|c|}
\hline $\begin{array}{l}\text { Chief Muruithia } \underline{\text { had }} \\
\text { been shot on his way }\end{array}$ & لدي يا أطلق \\
\hline
\end{tabular}
to Ndeiya (p.143)

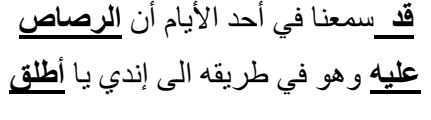

(p.266)

"We heard one day that he had been shot on his way to Ndeiya".

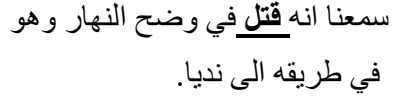

(p.230)

"We heard he was killed in broad daylight on his way to Ndeiya".

The expression "had been shot" refers to the act of killing somebody by shooting (Holder, 2008, p.161). This word that is frequently used in different events in "A Grain of Wheat" means executed. In the real world, the one word could not be a euphemism for the other (Rawson, 1981, p.255). However, "killed" involves an active human agent who acts deliberately; Hassen uses the word that gives dark side to the way of death. The term "تل is selected by Hassen to be an equivalent to the word "shot", which may be categorised as unpleasant to the readers of target text. While it works functionally, its connotation may lead to harshness in the rendition.

In contrast and in pursuit of the intended meaning, Mahfouz implies the way of killing the Chief figuratively, and he then made modification in his Arabic language. His translation made a difference in the text structure in the Arabic language.

The word "bullet" in the sense of modern usage: the shell being fired by a gun or a pistol or the like. This word has been stated in "Al-Waseet Dictionary". It is reported that this word is still used until today (Al-Waseet Dictionary; AlMunjed Dictionary; the Basic Dictionary and others). "أطلق عليه الرصاص is standard phrase in the Arabic language (Dictionary of Correct Language). As a result, Mahfouz succeeded in rendering the appropriate expression of euphemism in the source due to the employment of Lippehalme's standard translation strategy. 
Therefore, the rendition of such expression would also be possible if the translators employ Unseth's strategy "translate the original using different one that has similar meaning in the TL." The appropriate translation would be قضي عليه رمياً "بالرمي" " بالرصاص that means shooting by using a gun (Dictionary of the Contemporary Arabic Language, 2011).

To go deeper in both cultures of the source and target languages regarding death euphemistic expressions, there is necessity to consider the fact that dealing with death and dead people differs, undoubtedly.

In the following example, the author on (p.13) attempted again to use euphemistic expression for the same topic:

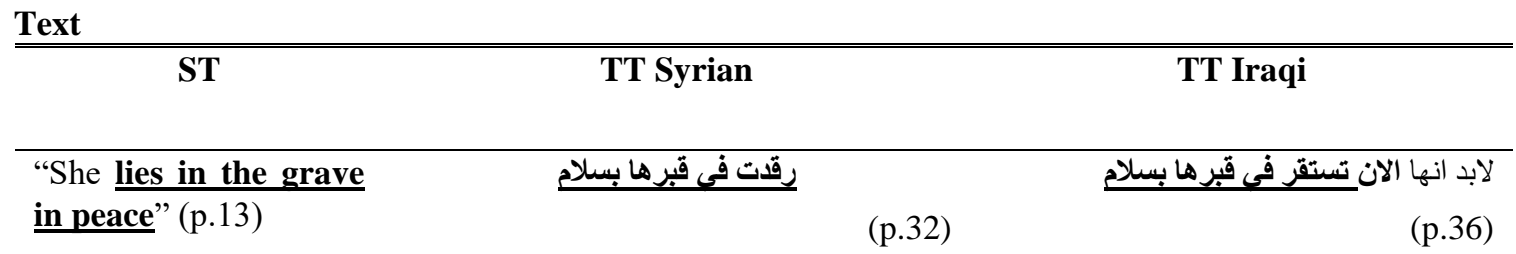

She went to rest in pease

She settled down in

the grave in pease

Author euphemistic expression that occurs in the form of death metaphor as a person's final fate is "She lies in the grave in peace". Using metaphors to express death events is one of the ways to avoid mentioning them. Rest: go to rest, "رقدت بسلام" is one of the terms that are all the inoffensive metaphors of death (Wehmeler, 1994, pp.582-584). Holder (2008, p.243) says "lay to rest", is, to inter a corpse.

Authors usually resort to consolatory metaphors, such as connotative metaphor which aims at evading the linguistic taboos die (Crespo Fernández 2007, p.11), with the intention of providing comfort to those left alive and assist them amidst the reality of the loss of loved persons. It is worth pointing out that, the common metaphors view death as a positive incident or as a sort of reward in Heaven.

The Arabic translations of this metaphor are semantically and pragmatically sufficient. Both Arab translators render it by using a common euphemism in Arabic (تستقر بسلام) and) ترقد بسلام) "She went to rest in pease" and "She settled down in the grave in pease". The translators' optimal and successful choice does not only reinforce the original euphemistic expressions, but it also represents a commonly used Arabic expression that communicatively renders the intended connotation in a context where literal rendition seems contented. Accordingly, the researcher of the current study suggests employment of Unseth's strategy "literal translation": (رقدت في قبر ها بسلام), "she lies down in her grave in peace”. " " " means sleep (Al-Ma’any Dictionary, 2004 and Al-Ghany Dictionary).

\subsection{Sex Euphemism}

Within the reference to topics relate to sex, Enright (2004) said that words with sexual connotations are basically dysphemistic so that there are still new euphemisms being coined. In "A Grain of Wheat", Ngũgi uses clustering of euphemisms around a given topic to reflect the strength of a particular taboo.

According to Rawson (1981), the area of taboos-related sex is greater than others. Thus, within this theme, the researchers of this study take some examples that examined in relation to English sex-related expressions, such as the next euphemism in (p.114):

\section{Text 1}

ST

TT Syrian

TT Iraqi

"To find a woman hardly
waited for him to disappear
round the corner, before she
rushed back to bed with
another man (114)

She rushed hastily to

bedroom of another man

اليجد امر اة لم تتنظر أن يختفي في زاوية إحضية

(p.184)

To throw herself into the

arms of another man

In this excerpt, "go to bed with" that is to copulate with (Holder, 2008, p.199). "Bed" is categorised as euphemistic word since it is a figurative word denoting "sexual intercourse". "Sexual intercourse" is offensive to say. It refers to sex activity between couple. The employment of euphemistic expression here is in order to avoid using the dispreferred expressions. Such words are considered taboos by many people.

One way to alter "sexual intercourse" is by covering it with euphemistic expression. Thus, the author of the ST uses "bed" (p.114), (p.112) and (p.178) as a euphemistic metaphor for the expression "sexual intercourse". It is because 
metaphors are figures of speech in which expressions literally specific things or events are used to others (Goossens, 1990). The exact connotation of "bed" goes to sexual activity conducted by lovers to express their feelings.

To support that, Hassen rendered the figurative expression "she rushed back to bed with another man" into " ترتمي في "حفي "

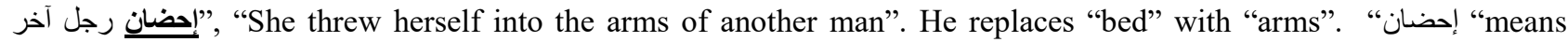
"somebody throws him/ herself into the arms of another person" (Al-Ma'any Dictionary; Lissan Al-Arab Dictionary, Al-Waseet Dictionary). This expression is considered euphemistic in Arabic language and can be used as figurative to refer to sexual intercourse. Hassen successfully replaced the word "bed" with the intended term. His rendition is acceptable since the meaning of the source expression is hidden. The word "إحضان!" (arms) used by the Iraqi translator undergoes semantic narrowing in which the new meaning gets narrower and less general than the source expression.

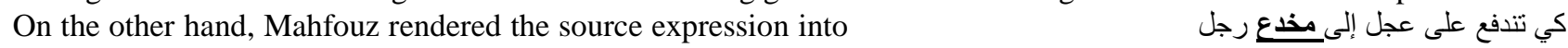
(آخر), "She rushed hastily to bedroom of another man". His translation is considered more literal. The use of the term "bedroom" gives readers reference to sexual intercourse directly. "Sexual intercourse" is a physical activity that takes place in the bedroom. Thus, the feature of bedroom refers to sexual activity. Whereas Mahfouz uses "bedroom" as a word that refers to the private room; a place where there will be a bed inside to do private activity. He uses the process of semantic change in which the new meaning is regarded less favourable by referring to the sex area. Consequently, while Hassen's translation is considered appropriate with regard to the source text, Mahfouz's translation gives the disprefered connotation.

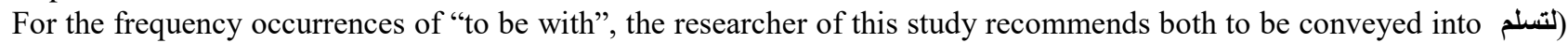

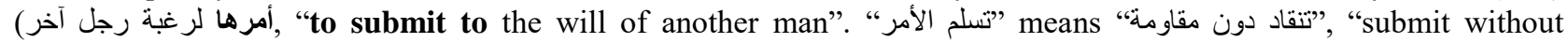
resistance" (Al-Waseet Dictionary; Al-Ghany Dictionary). Translation of such expression would be possible if the translators employ Leppihalme's strategy "replacement of the original item by a TL item".

Expert below in (p.6) illustrates another euphemism that was typically translated.

Text 2

$\begin{array}{llc}\text { ST } & \text { TT Syrian } & \text { TT Iraqi }\end{array}$

\begin{tabular}{|c|c|c|}
\hline \multirow{3}{*}{$\frac{\text { "Play with his thing" }}{\text { (p.6) }}$} & رجلاً ضخما يداعب قضيبه & حذفت الترجمة \\
\hline & (p.19) & \\
\hline & "Play with his Penis" & $\begin{array}{l}\text { No translation } \\
\text { is provided }\end{array}$ \\
\hline
\end{tabular}

This expression is verbal shorthand for anything one prefers not to discuss in detail. It is an omnibus term. The term "thing" has been used since medieval times for the sexual parts (Rawson, 1981). "Thing" is any taboo object one refers to it implicitly or allusively. Previously, it refers to a ghost. Now it refers to the penis or vagina (Holder, 2008). On the other hand, the verb "play" means to indulge in sexual activity.

Ngūgī selected this expression because he is acquainted with his people's culture, eupheming his expressions of sex in order to save his own face and others from the shame caused by obvious usage of such expressions. Translation of the word" thing" in of the source text into Arabic can adopt many translation strategies. While Mahfouz tried to stick to the customs of his conservative culture that makes the idea of conveying the name of sexual organ detested, Hassen deleted it. The translation adopted by Mahfouz is so close to the source text with some variation in form of addition because he was familiar with the euphemistic expression in the ST.

The euphemistic terms in the ST are not conventional words that would easily be recognised by casual readers, but they necessitate altering in order to understand the intentional connotations. This euphemising technique was employed as a novelty for the purpose of inviting the readers to search more for the meaning. However, Mahfouz conveyed the source euphemistic expression into "play with his penis". He employed a strategy that let euphemism be lost as dysphemism; play in Arabic language means "play with the fingers" (Lissan Al-A'arab Dictionary, 1968).

Hatim and Munday (2004) say that literal translations have a tendency to save formal features almost by default, i.e. with little or without consideration for contexts, meanings or what is implicit by given expressions. Mahfouz used "penis" as a substitute for man's outer sexual organ. He rendered the source expression literally, but with inappropriate functional translation. Such shifting may sound offensive and religiously forbidden. The translation of the euphemistic phrase necessitates modesty and public courtesy (Hornsby, 2007, p.42).

In addition, Mahfouz did not employ the strategy of using innovation with the intention of inviting the readers to search more the meanings. He did not give the impression that he recognized the indirect function of the euphemisms in the STs and thus focused on the main purposes of the expressions.

On the other hand, the SL was totally not translated into the TL because Hassen possibly was avoiding the translation strategy that might cause unpleasantness for a reader. In fact, Arabic words are governed by Islamic and cultural rules that pose sanctions on the use of disagreeable words whereas the native speakers of English have free implementation and sometimes adopt new euphemistic words borrowed from other languages and cultures (Qadi-Al-Nasser, 2009). Thus, the above mentioned expression has been completely censored in the Iraqi translation. It was as it removed for its contradiction to the Islamic beliefs of the target readers.

Leppihalme proposes that rendition of such phrases could be done by the use of omission. "This technique is used when a certain word of the original text has no correspondent in the TL, and when it does not vary the meaning of the text" 
(Baker (1992, pp.28-36). The use of this strategy assists to preserve the face of Arabic readers who might be using for a justification for on why the source sexual expression is omitted. Although Leppihalme's omission strategy may take the Arab culture away from cultural aspect but it could offer an appropriate method for translating sex expressions.

Another example is shown by the author in (p.97):

\begin{tabular}{|c|c|c|}
\hline ST & TT Syrian & TT Iraqi \\
\hline "I had made love to many & ضاجعت الكثير ات منهن في حياتي & حذفت الترجمة \\
\hline \multirow{2}{*}{$\begin{array}{l}\text { a woman but never had felt } \\
\text { like that before “ (p.97) }\end{array}$} & $(\overline{p .184)}$ & \\
\hline & $\begin{array}{l}\text { "I had copulated with many women } \\
\text { in my life" }\end{array}$ & $\begin{array}{r}\text { Translation is not } \\
\text { provide }\end{array}$ \\
\hline
\end{tabular}

\begin{tabular}{|c|c|c|}
\hline ST & TT Syrian & TT Iraqi \\
\hline \multirow{4}{*}{$\begin{array}{l}\text { "I had made love to many } \\
\text { a woman but never had felt } \\
\text { like that before " (p.97) }\end{array}$} & ضاجعت الكثير ات منهن في حياتي & حذفت الترجمة \\
\hline & (p.184) & \\
\hline & & \\
\hline & $\begin{array}{l}\text { "I had copulated with many women } \\
\text { in my life" }\end{array}$ & $\begin{array}{r}\text { Translation is not } \\
\text { provide }\end{array}$ \\
\hline
\end{tabular}

"I had made love to many

like that before " (p.97)

\section{Text 3}

Love making in this example means having sex, which makes reference to unlawful relation in the above mentioned case. If this expression is refered directly, it will be culturally offensive to Arab readers due to the prevailing Islamic laws that strongly forbid this kind of illegitimate sexual relation. In addition, the source language culture does not find it appropriate to mention sexual related words openly in all circumstances (Kecskes, 2016).

The first euphemism "copulated with" does lead to the intended meaning of the source language. Copulated with is considered euphemistic expression that presents the real statement of the connotative expression "having sexual relation". In the dictionary of euphemism of Holder (2008), "copulate with" means having sexual intercourse with women.

Mahfouz's translation of this expression is seen as the most appropriate. He determines the meaning behind the form in the SL and makes his efforts to generate similar meaning in the TL- using the form and structure of the TL.

On the contrary, Hassen did not convey the idea of practicing illegal sexual activities, which are abominable sins in Islam. He did not convey this text in the target language.

Subsequently, it is bet subsequently, it is better to express it using Unseth's strategy, namely translating the original text by using different euphemistic expression in the TL allowing the target readers to comprehend the contextual connotation. Warren (1992, p.33) states that interpretations vary in accordance with contexts; for example, whether the writers mean the expressions to be inoffensive, and the hearers understand them.

Ventola et al. (2004, p. 159) states that deletion strategy implies a complete loss of information of source expression that is used for literary aim. It can be seen that Mahfouz's translation is in contrast of Hassen's who leant towards applying the deletion strategy.

Therefore, the researcher suggests this interpretation (لقد لامست العديد من النساء), "I had touched varied women". "Touch" refers to intercourse (Dictionary of the Contemporary Arabic Language, 2011). Intercourse means physical contact with men (Holder, 2008, p.383). In this book titled "The Linguistic Differences, Abu Hilal Al-A'askari (pp. 249-250) says that the verb "touch" paves the way to the intercourse that begins with touching. "Touch" is specifically a euphemised reference to sexual intercourse through the implication of adopting dissimilar one that has similar meaning in the TL of the euphemised strategy defined by Unseth.

Further example on the same topic is as follows (p.133):

\section{Text 4}

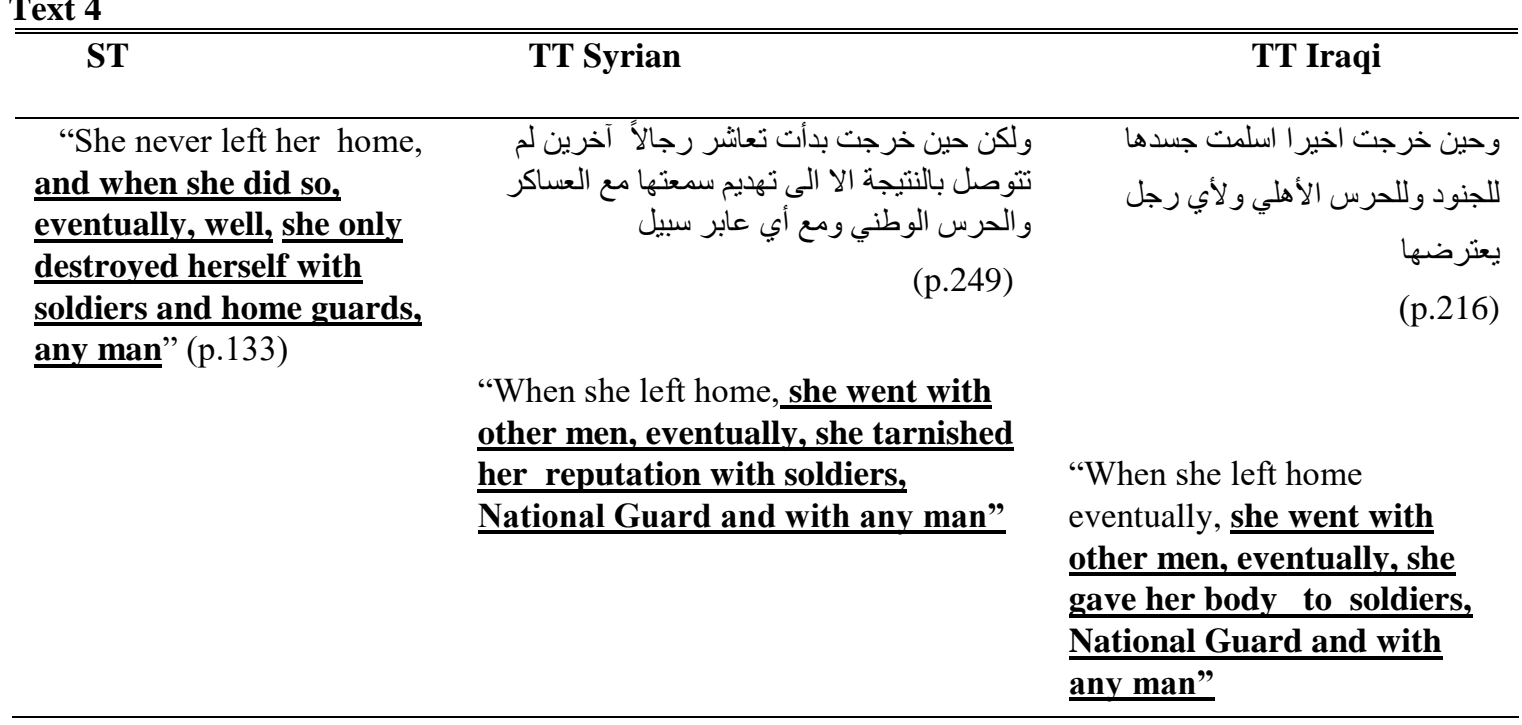

The metaphorical expression in the source text above "when she did so" refers to "have sex". This expression uses by the author of the novel to avoid mentioning profane expression functionally. This expression is rendered using free 
translation method. It is because the translators try to make it sound natural in the target language. Mahfouz does render the hidden meaning in the source metaphorical euphemism to the target readers through clarifying the source meaning term. He could achieve more directness by interpreting the intended meaning. His usage of the expression "تعانش”" (copulate with) is a

metonymy that is a euphemism for "have sex" to avoid mentioning an embarrassing term, namely, illegal sexual intercourse.

On the contrary, Hassen uses overtly literally translation by employing the word "body" to refer to illegal sexual intercourse. "أسلمت" in the Arabic language means "left or submit" (Lissan Al-A'arab; Al-Waseet and Asahah Dictionaries). Submit, such as submit the body to the pollution, that is, illegal intercourse (Holder, 2008, p.73). Thus, Hassen is influent in rendering both the intended meaning and the euphemistic term as rich as it is in the SL text.

The two translations succeeded in conveying the original meaning and style. Both words, " "ماسلمت" are slightly appropriate equivalents to the hidden connotative meaning "When she did". The two translations are acceptable. While Mahfouz's translation is not euphemistic expression because the meaning is shown clearly, Hassen's rendition presents reference to the source text that is a semantic narrowing process. He succeeded in employing Leppihalme's strategy "replacement": replacing the original text with accurate euphemism in the target language.

The next example shows another data on the sex topic found on (p.142):

\section{Text 5}

\begin{tabular}{|c|c|c|}
\hline ST & TT Syrian & TT Iraqi \\
\hline \multirow[t]{2}{*}{$\begin{array}{l}\text { "A number of women } \\
\text { secretly and voluntarily } \\
\text { offered themselves to the } \\
\frac{\text { soldiers for a little food" }}{\text { (p.142) }}\end{array}$} & 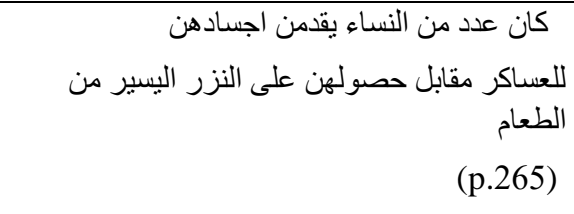 & $\begin{array}{r}\text { الجنود من اجل النسوة يعرضن انفسهن على } \\
\text { الطعام } \\
\text { (p.228) }\end{array}$ \\
\hline & $\begin{array}{l}\text { "A number of women offer } \\
\text { their bodies for the soldiers in } \\
\text { exchange for receiving a little food". }\end{array}$ & $\begin{array}{l}\text { "Some women offered } \\
\text { themselves to the soldiers for } \\
\text { food". }\end{array}$ \\
\hline
\end{tabular}

In the above example, "offer" means to ask men to copulate with usually promiscuously (Holder, 2008, p.281). This term is usually of a female making love with somebody (Holder, 2008, p.256). "Offer" means "give herself up to practice prostitution or to debauchery" (Holder, 2008, p.222). Meanwhile, "يعرض" or " in the Arabic language according to Lissan Al-a'arab and Asahah Dictionaries mean "يعطي" (give).

Mahfouz and Hassen, in interpreting this expression, mention that women were giving themselves in order to get some food. Their renditions lead to the intended meaning relationship of the source composition. Their use of the word "give" to replace the source text is communicatively successful. Thus, the two translations could convey the original data of "offer", which is an abominable sin in Islam. The translators produce the text in the target as rich as it is in the source. Euphemistic expression is retained and meaning is clear. Both of them employ Unseth's strategy "literal translation" that is clear cut-terms as much as English one.

6.3 Human Body Euphemistic Expressions

Allan and Burridge (1991) state that euphemisms seem to be culturally sensitive area in several languages and cultures, for instance, parts of body.

In the line of this analysis, it can be seen that the reference to body part was simply informative, such as sexual parts as "limbs". The semantic shifts give their shares, as limbs in the example below are used for "legs". This clearly oriented form of euphemism offers substitute to alleviate the potential risk of taboo expression in the employment of part of the body, orgasm, relationship, sexual play and sexual alternative. Excerpt (1), below, illustrates the part of the body that was typically replaced by another lexical selection.

In the next example, Ngūgī writes in this novel on (p.4) and (101) "limbs" as euphemistic word.

Text 1

\begin{tabular}{|c|c|c|}
\hline ST & TT Syrian & TT Iraqi \\
\hline $\begin{array}{l}\text { "Women had felt the } \\
\text { weight of those limbs" } \\
\text { (p.4) }\end{array}$ & شبرن وطأة بأن العديدات من النساء الثـابات قد & مِالكثير من الثـابات عرفن ثقل جسمه \\
\hline & $\begin{array}{l}\text { Many young women had experienced } \\
\text { his legs' weight over them. }\end{array}$ & $\begin{array}{r}\text { Many young women knew the } \\
\text { weight of his body. }\end{array}$ \\
\hline
\end{tabular}

In the excerpt set above, euphemistic term tends to refer to the body part in a way it escapes referring to the sexual function. The author of the novel mitigates the taboo usage of body part that denotes sexual function. His intention is 
the illegal sexual relations of the character with various women. The author speaks about body part by stating a reference to sexual expression. Limbs mean obsolete legs (Rawson, 1981; Holder, 2008). This classic example of the nineteenth century is considered to be presented in a more effective way for being more general; "limb" is broadly much-admired as one of the ultimate euphemisms.

The synonyms of the target texts translations were not identical. The utterance in the source language above is conveyed by Mahfouz by using word for word translation technique. He made some effort adding the word "over" to give emphasis to nature of the act between the character and the women. In this exegetical type of interpretation, Mahfouz gives further information not cited in the ST. His selection to the most widespread denotative meaning made some ambiguity in his interpretation. Accordingly, his usage of the word legs dysphemises the original text. On the other hand, Hassen successfully makes minimum change by using proper alternation "body" as the whole for the part "limbs" in the target text, making the utterance sounds more natural. In doing so, Hassen applied the Leppihalme's strategy of minimum change, which can be regarded as

literal translation.

The Arab translators have all followed the source expression very closely with common variations in the form of additions due to their familiarity with such kinds of euphemistic expression. A better translation would be possible, if the translators employ Leppihalme's strategy "replacement": (العديد من النساء قد خبرن رجولته) "Many women had known the secrets of his virility". Virility refers to the quality of having a strong sex (Al-Waseet Dictionary, 2004; Dictionary of the Contemporary Arabic Language, 2011).

In another example, Ngūgī writes in this novel on (p.95) "flesh" as euphemism.

\section{Text 2}

ST

TT Syrian

TT Iraqi

\begin{abstract}
But how could she fight with a demon who never put on the flesh of a woman (95)
\end{abstract}

\section{كيف لها ان تقاتل شيطانا لايكتسي \\ بلحم امراة \\ (p.181)}

how could she fight with a demon who never put on the flesh of a woman
كيف تقاتل شيطانا لا يتخذ

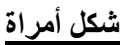

(p.161)

how could she fight with a demon who never put on the body of a woman

The word "flesh" was used by the author to refer to the part of the body. "Flesh" as part of body is essential to the continuation of life, usually the organ located in trunk (Holder, 2008, p. 396). We cannot be certain about the metaphorical meaning in the author's mind. In the event of the novel, Wambuku wanted to live with Kihika, the later seems churlish to refuse. She thought that there is a demon represented by a woman. "Flesh" here was used metaphorically to represent the genitalia of demon that made Kihika would not take the plunge with Wambuku.

Mahfouz employed literal translation to convey this word into "flesh" which means "meat". Here, Mahfouz uses hyperbole (overstatement) that is found in the euphemistic word like "meat" for "flesh". "Meat" means genitalia (Holder, 2008, p.43). This word has a multiple sense, namely primary and secondary meaning. The meaning relation is possibly derived by a variety of processes of semantic change; semantic shift is one of these processes. Mahfouz's rendition depends mainly on the process of semantic shift. The word "flesh" loses some aspect of its hidden meaning, taking on a partially new, but related connotation. In his rendition, Mahfouz conceals the hidden meaning in consideration that it is taboo as a part of body.

In the same way, Hassen resorts to rendering "flesh" into "body". He employs the translation of the part for the whole euphemism that means to take with something else demonstrated in "body" for female genital. The meaning is thus reduced vaguer than the direct term, aimed at hiding the unpleasant connotative referent. At this point, it is worth to come mentioning that ambiguity is one of the tools of euphemisms.

The two translators succeeded in conveying the original meaning. Both expressions "meat (flesh) and body" are slightly equivalent to the original term "flesh". Hassen's translation is more convincing than Mahfouz's translation, as he employs the replacement strategy to make the translation acceptable by using different euphemism.

Supporting the above illustration, the two Arabic translations would be possible if the Arab translators employ Leppihalme's strategy of "replacement by a TL item: كيف تقاتل شيطاناً لا يجس امر اة" "how could she " fight with a demon that never embodies a woman. The verb "يجسد" in the Arabic language means represent (Dictionary of the Contemporary Arabic Language, 2011).

\subsection{Urination, Defecation, Toilet Euphemism}

Most speakers do not have a desire to speak about toilet words or urination as these topics might cause unpleasantness. These days'euphemism is connected with lavatory and excretion in a large number (Holder, 2008).

In the next example below, the novelist uses another euphemistic expression on (p.213). 


\begin{tabular}{|c|c|c|}
\hline ST & TT Syrian & TT Iraqi \\
\hline $\begin{array}{l}\text { "The blood has been } \\
\text { split for this day. Not } \\
\text { blood from the ram } \\
\text { but from the veins } \\
\text { and skins of our sons } \\
\text { and daughters" (p.213) }\end{array}$ & $\begin{array}{l}\text { "The blood has been split for this day. } \\
\text { Each column in our hut but } \\
\text { deliberately baptised with blood. Not } \\
\text { the blood of the sacrifices but the } \\
\text { blood of our sons and daughters" }\end{array}$ & $\begin{array}{l}\text { The blood has been split for this day } \\
\text { that every person in our hut was not } \\
\text { baptised with the blood of sheep but } \\
\text { with the blood } \\
\text { of our sons and daughters" }\end{array}$ \\
\hline
\end{tabular}

The significance of blood in this novel is used to serve as a metaphor for the breakdown of the whole human being (Samwiteros). In this metaphor, the word "body" may represent the meaningful sacrifice of people in their bodies. Spilled or lost blood signifies struggle against colonialism. Blood has been used as a euphemism to describe one's martyrdom. In fact, using metaphor encourages interpretation as it gives options within the meaning of what translators want to convey. The reason behind the use of metaphor is to describe the event, entity and quantity in a more comprehensive and complex method (Liang \& Liu, 2015).

Metaphorical expression could be interpreted by adopting various options such as reproduction, replacement and reduction (Newmark, 1988, pp.108-111). The strategies of Leppihalme and Unseth include the same strategies identified by Newmark. Reproduction means that the source text should be translated by a metaphor in the target text, unless the target text metaphor does not have an equivalent in the related TL register (Mason, 1982).

The above mentioned metaphorical expression was translated into the targeted texts by the both translators in unlike ways, taking into account the words employed by them. Mahfouz substituted the blood of ram with the blood of animals or a person that is offered to God, to a divine or supernatural figure that had covered each column in their home to give comprehensive outlooks about the event of the text's time to his readers. In contrast, Hassen conveyed inappropriately the source figure of speech in a more literal way. He used blood of sheep for the blood of vein and skins of sons and daughters. Sheep here was used by Hassen as an equivalent to the word "ram". This expression will cause misunderstanding of the actual connotation of the source text adopted by the Kenyan novelist to the text readers. Indeed, as Dweik and Abu Shakra (2010) stated, if translators rely only on literal translation to translate different structures and phrases, they without any doubt, will end up with an incomprehensible text which will cause a big misunderstanding and confusion on the readers. Also they will not be able to transfer the message that the texts carry because they only focus on searching corresponding words.

Sameerah and et al. (2016) stated that the employment of Leppihalm's strategy "reduction" would be the suitable strategy in this case. When texts are reduced, the semantic contents remain sound while the lexico-grammatical structures used for conveying those contents are reduced. In contrast, if texts are decimated, then a part of the semantic content is given up (Ventola et al., 2004, p. 159). The reduction of the original phrase could be done by producing a comparable expression in the Arabic language. Thus, the proposed translation is (جلم أبناؤنا وبناتنا تضحيات كبيرة من ( (اجنا (التضحية" "Oefers to the person's sacrifice either with blood or money or things (Al-Ma'any Dictionary).

Let us consider the next English excerpt used by the novelist repeatedly on (p.6), (p.44) and (p.143).

\section{Text 2}

ST

He dug a little, and feeling the desire to pass to water (p.6)

\section{TT Syrian}

شعر برغبته في التبول

(p.18)

\section{He had a desire to piss}

\section{TT Iraqi}

\section{كانت لديه حاجة الى التبول}

(p.24)

\section{He had a need to}

piss.

In example (22) above, the English euphemistic expression "to pass to water" was rendered by Mahfouz in each sentence included into "a desire to piss" and Hassen rendered it first and second time into "a need to piss", but he intentionally omitted the translation of this expression in the third. The example shows that both Arab translators in their literally as "piss" by both translators. This replacement is too harsh and extremely embarrassing to the Arabic readers.

In "A Dictionary of Euphemisms and other Doubletalk" for Rawson (1981) and "How Not to Say What You Mean": A Dictionary of Euphemisms" for Holder (2008), this explanation "pass the water" is used instead of "to piss". The "water" is the euphemism. "Water" has stood for "urine" for the past 600 years or so. "A famous example comes from the first of the articles of impeachment against Quinbus Flestrin, aka the Man-mountain: "Whereas, by a statute made in 
the reign of his Imperial Majesty Calin Deffar Plune, it is enacted, that whoever shall make water within the precincts of the royal palace, shall be liable to the pains and penalties of high treason..."(Jonathan Swift, Gulliver's Travels, 1726). In this vein, the Arabic interpretations seem inadequate. Both translators have not explored the proper strategy for conveying the euphemistic function since the ST intended connotation is to express this meaning in a polite way. Therefore, the best solution for conveying this expression is by using the strategy proposed by Unseth, which is to translate the original expression by using a different expression of similar meaning in the TL. Therefore, the more appropriate translation is “ يقضي حاجته (Dictionary of The Contemporary Arabic Language, 2011), which means

"Relieve Oneself".

The expression lavatory was adopted on (p.9) in the following example:

Text 3

\begin{tabular}{lcrl}
\hline \hline \multicolumn{1}{c}{ ST } & TT Syrian & TT Iraqi \\
\hline $\begin{array}{l}\text { He entered the pit } \\
\text { lavatory. (p.9) }\end{array}$ & (p.28) & \\
\hline
\end{tabular}

"He is deliberately dropped

"He Entered the toilet."

something inside the pit

of toilet."

Lavatory used to denote to place, that is, to wash yourself (Carter, 2001). In fact, it is adopted to indicate a vessel for washing purpose, such as a wash basin. Therefore, it came to denote to a room with washing vessels (Hanks, 2013). Since such rooms often contain toilets, the meaning developed into its present meaning, explicitly the mannerly and formal euphemistic expression for toilets and the rooms having them (Shove \& Warde, 2002).

According to Rawson (1981, p.164) lavatory is a Latinate washroom, sometimes used for the principal fixture and for the place. "Lavatory," sometimes abbreviated in Britain to lav, derives from the Latin lavare, to wash. Prior to the nineteenth century, a lavatory really was a place for cleaning up. Therefore, the typical convent had a lavatory which was for washing. Holder (2008) says; this Latin word is used as a place for washing in. It generally denotes original and common structures, as in the army.

The author created this word as euphemism. However, in the back translations, Mahfouz and Hassen, did not convey the original meaning in the novel, instead they replaced culturally this word using common word "toilet". In fact "lavatory" is the room which contains toilet. Their translation is considered inadequate because they adopted a direct term that may give a limited idea to the minds of target readers as a place of urination.

What is more is that, Hassen omitted some information included in the source text; such attempts cause missing the more general function of the source expression.

In this content, Unseth offers literal translation as a solution for the rendition of such words. The researcher of the current study suggests the use of "دورة المياه" that means "bathroom" (Dictionary of Contemporary Arabic Language, 2011; Al-Waseet Dictionary, 2004; Al-Ghany Dictionary). "دورة المياه" is a suitable rendition for the above euphemistic word.

\section{Conclusion}

This article discusses the influence of sociocultural differences in translating euphemisms in "A Grain of Wheat". Since, the objective reason behind using the euphemistic expression in literature works is to save the author's his readers from the embarrassment that might be created from the employment of definite expressions, translators must exert their efforts to find the appropriate euphemistic equivalents in their translations to avoid cultural gap.

Newmark (1988, p.94) says:" there will be a translation problem unless there is cultural overlap between the SL and the TL. However, language does contain all kinds of cultural deposits. Most cultural words are easy to detect, since they are associated with a specific language and cannot be literally translated. Literal translation would alter the meaning and a translation may include an appropriate equivalent.

Having discussed of euphemistic expression from sociocultural effect, the researchers have come to the conclusion the influence of sociocultural differences in Translating Euphemistic Expressions from English into Arabic in "A Grain of Wheat". It can be concluded that both two Arabic translations have all followed closely the original literal translation texts with some variations. Twenty four examples indicated that literal, omission, and replacement translation strategies are frequently applied to translating the four topics: death, sex, human body and bodily function in "A Grain of Wheat". In fact, both translators used three strategies, namely literal, omission and structure change to preserve the SL flavour and integrity. Both translators also strived to keep the meaning in the source texts sound natural by transferring the SL's structure. Omission and literal strategy employed by the translators frequently may not express euphemistic words functionally. The findings also revealed that both translators attempted to translate semantically the euphemistic expressions but at the expense of rendering them adequately into the target culture. While the researcher found similarities and differences in the employment of translation strategies in translating the euphemistic expressions, the 
Syrian translation is apparently better delivered than the Iraqi translation. The findings also suggested that knowledge and competence of the translators in handling sociocultural differences as well as the employment of effective strategies such as those proposed by Leppihalme and Unseth are indispensable tools for solving the problems of translating euphemistic expressions.

\section{References}

Abdul-Raof, H. (2013). Qur'an translation: Discourse, texture and exegesis. Routledge.

Alkire, S. (2002). Introducing euphemisms to language learners. The Internet TESL Journal, 8(5).

Allan, K., \& Burridge, K. (1991). Euphemism \& dysphemism: Language used as shield and weapon. Oxford University Press, USA.

Allan, K., \& Burridge, K. (2006). Forbidden words: Taboo and the censoring of language. Cambridge University Press.

Baker, M. (1992). In other words: A course book on translation. London and New York: Routledge.

Charaudeau, P. (1998). Discours médiatique de l'information. INA, Paris

Cho, H. (2014). 'It's very complicated'exploring heritage language identity with heritage language teachers in a teacher preparation program. Language and Education, 28(2), 181-195.

Claire, E. 1998. Dangerous English 2000!: An Indispensable Guide for Language

Learners and Others. USA: Delta Publishing Company.

Crespo-Fernández, E. (2015). Sex in Language: Euphemistic and Dysphemistic Metaphors in Internet forums.

Bloomsbury Publishing.

Dhika, S., \& Gede, I. (2014). Euphemism an Dysphemisim in the movie Remember Me. HUMANIS, 19(1).

Efendi, C., Rosa, R. N., \& Wahyuni, D. (2013). Forms and types of Euphemism found on Sites of TEMPO. CO and YESS-ONLINE. COM. E-Journal English Language and Literature, 2(1).

Emanatian, M. (1995). Metaphor and the expression of emotion: The value of cross-cultural perspectives. Metaphor and Symbol, 10(3), 163-182.

Farghal, M. (1995). Euphemism in Arabic: A Grecian interpretation. Anthropological Linguistics, (37), (3), (366-378).

Goossens, L. (1990). Metaphtonymy: the interaction of metaphor and metonymy in expressions for linguistic action. Cognitive Linguistics (includes Cognitive Linguistic Bibliography), 1(3), 323-342.

Gross, J. T., \& Gross, I. G. (2012). Golden harvest: Events at the periphery of the Holocaust. Oxford University Press.

Hatim, B., \& Munday, J. (2004). Translation: An advanced resource book. Psychology Press.

Holder, R. W. (2008). Dictionary of euphemisms. Oxford University Press.

Hughes, G. 2006. An Encyclopedia of Swearing: The Social History of Oaths,

Profanity, Foul Language, and Ethnic Slurs in the English-speaking World.

New York: M.E. Sharpe, Inc.

Kecskes, I. (2016). Situation-bound utterances in Chinese.

Larson, Mildred. 1998. Meaning Based Translation. USA: University Press of America

Leppihalme, R. (1997). Culture bumps: an empirical approach to the translation of allusions (Vol. 10). Multilingual matters.

Liang, M., \& Liu, J. (2015). Translating Conceptual Metaphors in Chinese Stock News Report: A Web-Based Study. English Language and Literature Studies, 5(3), 118.

Munday, J. (2009). Introducing translation studies: Theories and applications. Routledge.

Musfiroh, U. N. (2014). A Study of Euphemism Used by President Barack Obama in the First Inaugural Address. Jurnal Ilmiah Mahasiswa FIB, 3(9).

Newmark, P (1988), Textbook of Translation. Oxford: Pergamon Press.

Nida, E. A. (1964). Toward a science of translating: with special reference to principles and procedures involved in Bible translating. Brill Archive.

Persell, C. H., \& Cookson Jr, P. W. (1987). Microcomputers and elite boarding schools: Educational innovation and social reproduction. Sociology of Education, 123-134.

Prasetyo, A. (2015). Application of B. Warren's model to political Euphemisms in United States Presidential Debate 2012. Language Horizon, 3(1).

Unseth, P., \& Unseth, P. (2006). Watch your language!: translating euphemisms. ATA Chronicle February, 2006, 3537.

Rawson, H. (1981). dictionary of euphemisms \& other doubletalk. Crown.

Samoškaite, L. (2011). 21st century political euphemisms in English newspapers: semantic and structural study. 
Shehab, E., Qadan, A. R., \& Hussein, M. (2014). Translating contextualized Arabic euphemisms into English: sociocultural perspective. Cross-Cultural Communication, 10(5), 189.

Shifa, L. (2013). Translation methods in "A Walk to Remember" novel translated into "Kankukenang Selalu”. Skripsi, Fakultas Ilmu Budaya.

Susan, B., \& Lefevere, A. (1990). Translation, history and culture. London and New York: Pinter.

Venuti, Lawrence. The Scandals of Translation: Towards an Ethics of Difference. London and New York: Routledge.

Ventola, E., Cassily, C., Kaltenbacher, M., 2004. Perspectives on Multimodality. Amsterdam: John Benjamins Publishing Company.http://dx.doi.org/10.1075/ddcs.6

\section{On-line Sources}

Al-Ma'any Dictionary

Al-Mourad Dictionary

Dictionary of the Contemporary Arabic Language, 2011

Al-Waseet Dictionary

Samwiterso: Analysis of Literary samwiterson.blogspot.com/2011/07/analyisis-of-literary-devices.htmlDevices 